\title{
Beyond Blindsight: Properties of Visual Relearning in Cortically Blind Fields
}

\author{
Anasuya Das, ${ }^{1,2}$ Duje Tadin, ${ }^{1,3,4}$ and Krystel R. Huxlin ${ }^{1,3,4}$ \\ ${ }^{1}$ University of Rochester Flaum Eye Institute, Rochester, New York 14642, ${ }^{2}$ Neuroscience Graduate Program, University of Rochester Medical Center, \\ Rochester, New York 14642, ${ }^{3}$ Department of Brain \& Cognitive Sciences and ${ }^{4}$ Center for Visual Science, University of Rochester, Rochester, New York 14627
}

Damage to the primary visual cortex (V1) or its immediate afferents results in a dense scotoma, termed cortical blindness (CB). CB subjects have residual visual abilities, or blindsight, which allow them to detect and sometimes discriminate stimuli with high temporal and low spatial frequency content. Recent work showed that with training, discriminations in the blind field can become more reliable, and even reach consciousness. However, the narrow spatiotemporal bandwidth of blindsight limits its functional usefulness in everyday vision. Here, we asked whether visual training can induce recovery outside the spatiotemporal bandwidth of blindsight. Specifically, could human CB subjects learn to discriminate static, nonflickering stimuli? Can such learning transfer to untrained stimuli and tasks, and does double training with moving and static stimuli provide additional advantages relative to static training alone? We found $\mathrm{CB}$ subjects capable of relearning static orientation discriminations following single as well as double training. However, double training with complex, moving stimuli in a separate location was necessary to recover complex motion thresholds at locations trained with static stimuli. Subjects trained on static stimuli alone could only discriminate simple motion. Finally, both groups had approximately equivalent, incomplete recovery of fine orientation and direction discrimination thresholds, as well as contrast sensitivity. These results support two conclusions: (1) from a practical perspective, complex moving stimuli and double training may be superior training tools for inducing visual recovery in $\mathrm{CB}$, and (2) the cortically blind visual system can relearn to perform a wider range of visual discriminations than predicted by blindsight alone.

Key words: contrast sensitivity; direction discrimination; hemianopia; orientation discrimination; perceptual learning

\section{Introduction}

Cortical blindness $(\mathrm{CB})$ is a severe loss of vision that follows damage to the primary visual cortex (V1). Even when a single visual hemifield is affected, individuals with CB are significantly impaired while performing day-to-day activities, such as reading, driving, and navigating (Gutteridge and McDonald, 2004; Das and Huxlin, 2010). Clinically, the predominant opinion remains that vision cannot be recovered in cortically blind fields (Pollock et al., 2011).

However, numerous studies have shown that CB subjects possess residual visual abilities in their blind fields, a phenomenon termed "blindsight" (Weiskrantz et al., 1974). Blindsight differs from normal vision in many ways: (1) it is largely unconscious (Weiskrantz et al., 1995; Sahraie et al., 2010b); (2) it is elicited

\footnotetext{
Received March 17, 2014; revised June 13, 2014; accepted July 7, 2014.

Author contributions: K.R.H. designed research; A.D. and K.R.H. performed research; A.D., D.T., and K.R.H. contributed unpublished reagents/analytic tools; A.D., D.T., and K.R.H. analyzed data; A.D., D.T., and K.R.H. wrote the paper.

We thank Marisa Carrasco for her thoughtful, constructive comments on the manuscript. We also thank Terrance Schaeffer for performing the Humphrey visual-field tests on all subjects and Aaron Levi for collecting some of the same-different task data. This work was supported by grants from the National Institutes of Health (EY021209) and the Schmitt Foundation, and by an unrestricted grant from the Research to Prevent Blindness (RPB) Foundation to the Flaum Eye Institute. K.R.H. is an RPB Lew R. Wasserman Merit Award recipient.

The authors declare no competing financial interests.

Correspondence should be addressed to Krystel R. Huxlin, PhD, University of Rochester Flaum Eye Institute, 210 Crittenden Blvd, Box 314, Rochester, NY 14642. E-mail: huxlin@cvs.rochester.edu.

DOI:10.1523/JNEUROSCI.1076-14.2014

Copyright $\odot 2014$ the authors $\quad 0270-6474 / 14 / 3311652-13 \$ 15.00 / 0$
}

most reliably by large ( $\geq 4^{\circ}$ in diameter) stimuli (Sahraie et al., 2008); and (3) it appears narrowly tuned in the spatiotemporal domain, with best performance at spatial frequencies between 0.5 and 2 cycles/ ${ }^{\circ}$ (Barbur et al., 1994; Morland et al., 1999; Sahraie et al., 2003) and temporal frequencies between 5 and $20 \mathrm{~Hz}$ (Weiskrantz et al., 1991; Sahraie et al., 2008). This constitutes only a portion of the spatiotemporal range exhibited by normal (intact) vision (Campbell and Green, 1965; Campbell and Robson, 1968; Roufs, 1972; Kelly, 1975, 1979). As a result, static, fine-grained stimuli (with high spatial frequency content) or those lacking sufficiently high temporal frequency content (in the form of transients, flicker, or motion) do not elicit reliable detection in $\mathrm{CB}$ fields (Hess and Pointer, 1989; Weiskrantz et al., 1991; Morland et al., 1996; Sahraie et al., 2003, 2008).

Nevertheless, encouraged by the existence of residual abilities in CB fields, several groups have used perceptual training techniques to try to recover vision or, at the very least, improve blindsight in CB (Sahraie et al., 2006, 2010a; Raninen et al., 2007; Huxlin et al., 2009). Given blindsight as the motivation for these studies, all these training paradigms used stimuli matched to the spatiotemporal bandwidths of blindsight. This leaves unanswered an important question: can subjects with $\mathrm{CB}$ recover vision outside the spatiotemporal bandwidth of blindsight? In addition to having obvious clinical implications, answering this question will yield important evidence pointing to the nature of neural changes that could underlie vision recovery in $\mathrm{CB}$. 
Table 1. Participant demographics

\begin{tabular}{|c|c|c|c|c|c|c|c|c|c|}
\hline & CB1 & CB2 & CB3 & CB4 & CB5 & CB6 & CB7 & CB8 & CB9 \\
\hline Gender & Female & Female & Male & Male & Male & Male & Male & Female & Male \\
\hline Age (years) & 29 & 52 & 43 & 68 & 62 & 62 & 64 & 59 & 77 \\
\hline Time after lesion (months) & 5 & 10 & 6.5 & 14 & 9 & 30 & 226 & 33 & 16 \\
\hline \multicolumn{10}{|l|}{ Corrected visual accuity } \\
\hline Left eye & $20 / 20$ & $20 / 20$ & $20 / 20$ & $20 / 20$ & $20 / 20$ & $20 / 20$ & $20 / 20$ & $20 / 20$ & $20 / 20$ \\
\hline Right eye & $20 / 20$ & $20 / 20$ & $20 / 20$ & $20 / 20$ & $20 / 20$ & $20 / 20$ & $20 / 20$ & $20 / 20$ & $20 / 20$ \\
\hline \multicolumn{10}{|l|}{ Training eccentricity (degree) } \\
\hline Orientation & 6 & 11 & 11 & 9 & 16 & 8 & 14 & 13 & 6 \\
\hline Direction & Not applicable & Not applicable & Not applicable & 13 & 13 & 9 & 8 & 7 & 7 \\
\hline
\end{tabular}

${ }^{a}$ Measured during 24-2 Humphrey perimetry in decibels (dB), averaged between the two eyes.

Here we asked whether visual discrimination learning in $\mathrm{CB}$ fields could be elicited by stimuli that do not normally elicit blindsight. Specifically, we sought to determine whether a simple orientation discrimination task using static nonflickering Gabors could be relearned de novo in CB fields-i.e., without prior exposure or training with moving or flickering stimuli. Second, we asked whether visual relearning induced by such training transferred to untrained stimuli and tasks, including fine (as opposed to just coarse) orientation discrimination and both simple and complex motion discrimination. Finally, we asked whether double training with direction and static orientation discrimination tasks provided greater generalization of learning relative to single training.

\section{Materials and Methods}

\section{Subjects}

Nine adult CB observers participated in the study (average age, $57 \pm 14$ years; range, 29-77 years; three females and six males). All subjects were $\geq 5$ months poststroke, with unilateral $\mathrm{V} 1$ damage causing homonymous visual field defects (for demographics, see Table 1). They were selected from a larger group of potential CB subjects of either gender because they met the following enrollment criteria: (1) unilateral occipital damage verified by inspection of structural MRI scans (Fig. 1); (2) stable, homonymous visual-field defects at the time of recruitment, as measured by Humphrey perimetry (Fig. 1); and (3) stable, accurate fixation. All CB subjects underwent psychophysical mapping of the borders of the impaired visual field before the commencement of training. Fixation accuracy was first assessed during Humphrey perimetry using a built-in eye tracker. Subjects were excluded from the study if they broke fixation on $>20 \%$ of fixation trials, which is considered "low test reliability" in Humphrey perimetry. If they passed this first test, subjects' fixation stability was assessed in the laboratory with an infrared eye tracker (ISCAN RK464), which tracked a single eye. As in our prior work (Huxlin et al., 2009), subjects were excluded if they were unable to maintain fixation in a $2 \times 2^{\circ}$ fixation window for $1500 \mathrm{~ms}$ while performing visual discrimination tasks in their periphery. In addition, we also excluded subjects with ocular problems (cataracts, retinal disease, glaucoma), an abnormal neuro-ophthalmological exam, and any neurological or cognitive impairments that would prevent them from training correctly. In particular, none of the subjects who participated exhibited visual or other forms of neglect.

\section{Equipment/display}

Visual discrimination tasks were performed on a Macintosh G4 computer running our custom psychophysics software with stimuli displayed on a linearized 19 inch Nanao CRT with a $75 \mathrm{~Hz}$ frame rate. Luminance resolution was extended using a Pelli adaptor (Pelli and Zhang, 1991). Subjects were tested in a dimly lit room and had their head stabilized in a chinrest, so that their eyes would be $\sim 42 \mathrm{~cm}$ in front of the monitor. To ensure that subjects were able to view the stimuli clearly, we measured their refractive correction for a viewing distance of $42 \mathrm{~cm}$. They were then fitted with custom frames and lenses rounded to the nearest half diopter.

Fixation was controlled in real time using ISCAN RK426 eye tracker (ISCAN) whose infrared camera monitored both the pupil center and corneal reflection of the right eye as described previously (Huxlin et al., 2009). Limits were set so that if subjects' eye moved by $>1^{\circ}$ from the fixation target in any direction during presentation of a visual stimulus (i.e., we used a $2 \times 2^{\circ}$ fixation window), a loud tone sounded and the trial was aborted, recorded as a fixation break, and excluded from the analysis.

\section{Psychophysical procedures}

Baseline measures of visual performance. For all tasks, each trial was initiated in a gaze-contingent manner. Subjects were asked to maintain fixation within the $2 \times 2^{\circ}$ window for $1000 \mathrm{~ms}$ (Fig. 2C,D). Following steady fixation, the stimulus appeared, signaled by a tone. All stimuli were presented for $500 \mathrm{~ms}$ and subjects had to maintain fixation until the stimulus and the fixation target disappeared, signaling the end of the trial (Fig. 2C,D). Subjects indicated their responses by key presses. Feedback was then provided by means of different tones that indicated a correct or incorrect response. To avoid response biases, a correction procedure was used to detect any sequence of three incorrect responses to the same presentation. When this occurred, the trial was repeated until the subject made a correct response. Data obtained during correction procedures were recorded but were not included in threshold calculations.

Ten tasks were used to measure visual performance. Six tasks involved motion direction discrimination and four involved static orientation discrimination (Table 2). To better differentiate between tasks, each task is numbered sequentially in the paragraphs below. For both direction and orientation, we used coarse discrimination tasks (left vs right direction; and vertical vs horizontal orientation) and fine discrimination tasks (discriminating small differences in direction and orientation).

Coarse direction discrimination tasks. Subjects discriminated $180^{\circ}$ direction differences using either random dot stimuli (Tasks 1-3) or luminance-modulated sine wave gratings (Tasks 4 and 5). All random dot stimuli contained dots presented at a density of 2.6 dots $/{ }^{\circ 2}$ within a circular aperture $5^{\circ}$ in diameter. Individual dots were $0.06^{\circ}$ in diameter and moved at a speed of $10 \% \mathrm{~s}$ for a lifetime of $250 \mathrm{~ms}$ (half the stimulus duration). Dots were dark $\left(0.5 \mathrm{~cd} / \mathrm{m}^{2}\right)$ and presented on a bright background $\left(23 \mathrm{~cd} / \mathrm{m}^{2}\right)$ to minimize light scatter.

Task 1 measured normalized direction range (NDR) thresholds for left-right direction discrimination, as described previously (Pasternak et al., 1990; Huxlin et al., 2009). In brief, this task estimated the broadest distribution of dot directions for which subjects could correctly discriminate global direction of motion to the left or right. To do this, dots were repeatedly displaced in a direction chosen randomly from a uniform distribution around the leftward or rightward direction axis, with a new set generated on each frame. NDR thresholds were expressed as a percentage of the maximum range of directions in which dots could move $\left(360^{\circ}\right)$ using the following formula: NDR threshold $(\%)=\left[360^{\circ}-\mathrm{di}-\right.$ rection range $(\mathrm{DR})$ giving $75 \%$ correct performance] $/ 360^{\circ} \times 100$. 

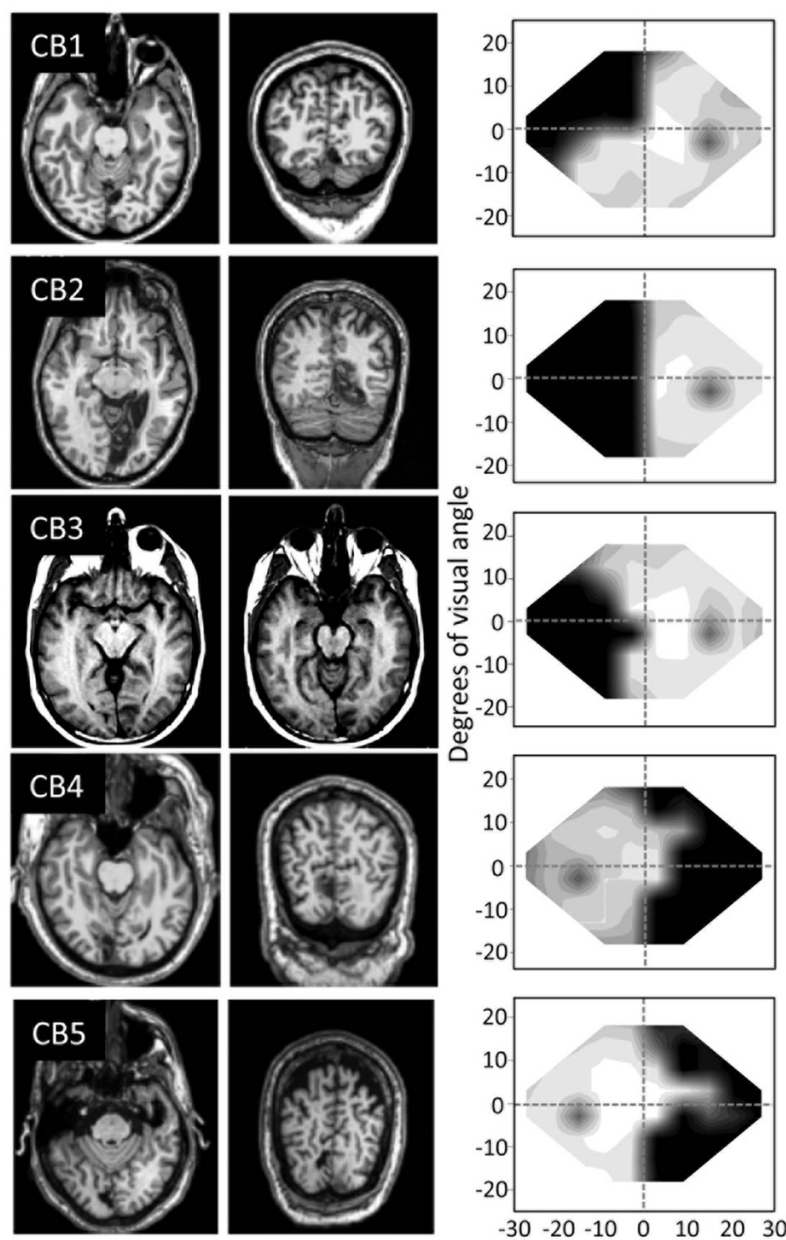

象
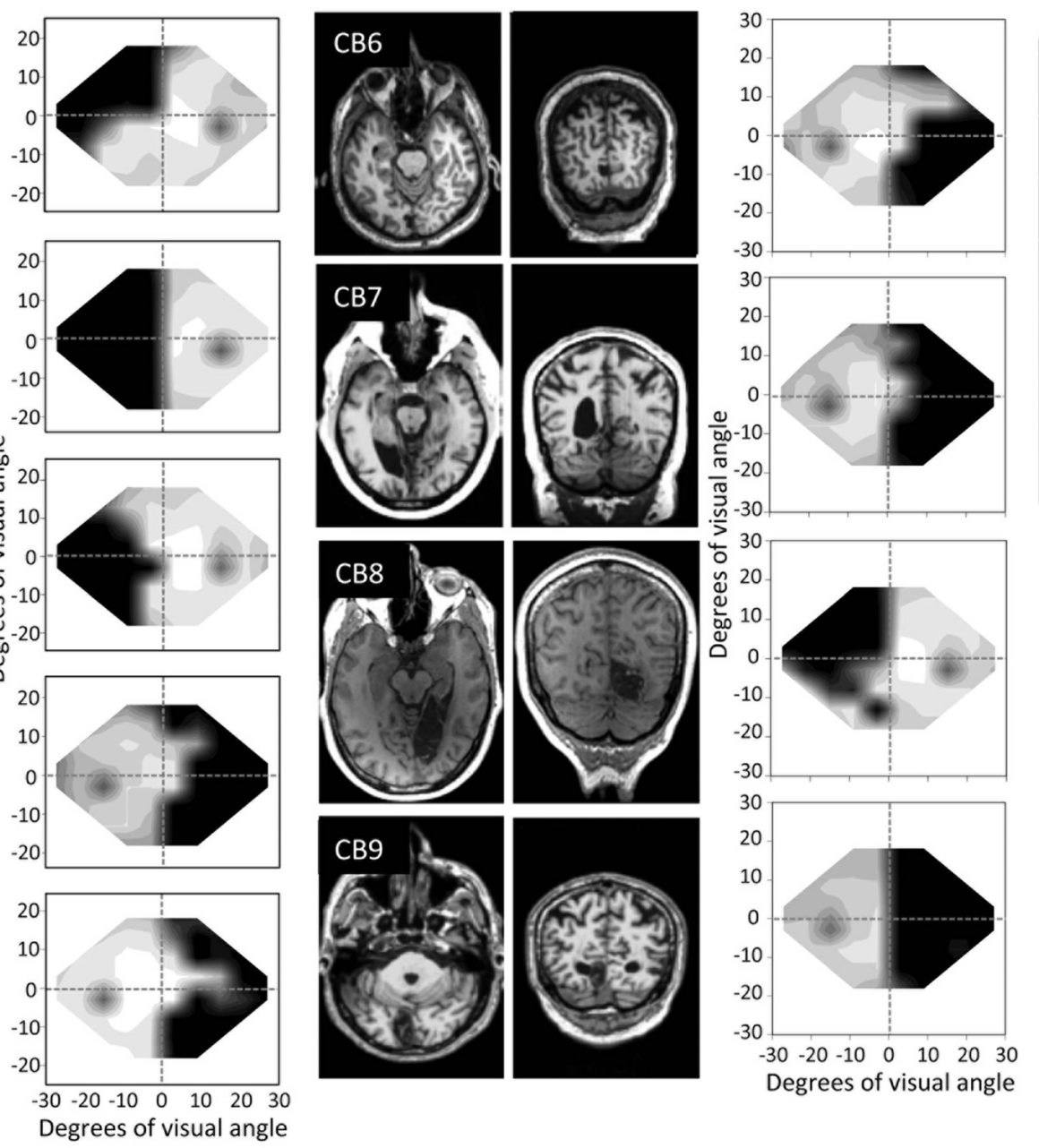

Degrees of visual angle $\begin{array}{lllllll}-30 & -20 & -10 & 0 & 10 & 20 & 30\end{array}$

Degrees of visual angle

Figure 1. Structural MRIs of the nine cortically blind subjects (CB1-CB9) that participated in this study, illustrating the location of their V1 damage. For all but CB3, the images are T1-weighed structurals in both horizontal and coronal planes. For CB3, both images are in horizontal plane, as his coronal scans were not of sufficient quality to resolve the lesion. Left is left and right is right on each MRI picture. Next to each subject's brain scans are representations of their Humphrey 24-2 visual field perimetry, averaged across the two eyes. The gray scale indicates average luminance detection sensitivity in decibels across the central 24 or so degrees of visual angle in each person's visual field.

Using this formula, lower numbers indicate better performance (in accordance with other threshold measures presented in this paper).

Task 2 measured motion coherence thresholds using random dots stimuli in which the ratio of signal dots (moving coherently to the left or right) to noise dots was systematically varied from high to low during each session (Newsome and Paré, 1988).

Task 3 measured direction range thresholds for $180^{\circ}$ direction difference discriminations around the trained directional axis $\left(0^{\circ}\right.$ or left-right discrimination), as well as three untrained axes: two oblique axes (30 and $60^{\circ}$ ) and the vertical axis. This task was only used after training to assess transfer of learning to untrained directional axes.

Task 4 used sine wave gratings to measure contrast sensitivity for moving stimuli. Specifically, moving gratings were presented in a circular aperture ( $5^{\circ}$ in diameter) and drifted either to the right or the left. The mean display luminance was $20 \mathrm{~cd} / \mathrm{m}^{2}$ and stimulus duration exhibited a $250 \mathrm{~ms}$ raised cosine temporal envelope. Contrast thresholds (Michelson contrast) were measured for spatial frequencies between 0.34 and 8.5 cycles $/{ }^{\circ}$, with temporal frequency fixed at $10 \mathrm{~Hz}$, and for temporal frequencies between 0.2 and $20 \mathrm{~Hz}$ with the spatial frequency fixed at 1 cycle $/^{\circ}$.

Task 5 assessed coarse perception of highly visible motion stimuli by measuring percentage correct performance for discriminating left-right motion direction of high-contrast moving gratings (Michelson contrast, 95\%; spatial frequency, $1 \mathrm{cycle} /{ }^{\circ}$; temporal frequency, $10 \mathrm{~Hz}$ ).

Coarse orientation discrimination tasks. Subjects discriminated $90^{\circ}$ orientation differences using static nonflickering Gabor patches that were either vertical or horizontal, presented within a Gaussian aperture extending $5^{\circ}$ in diameter, with $\sigma=1^{\circ}$. Gabor patches were presented using a $250 \mathrm{~ms}$ raised cosine temporal envelope and their space-averaged luminance was computed to be the same as that of the background to avoid stimulus detection as a result of changes in total light flux.

Task 6 measured contrast thresholds (Michelson's contrast) while subjects discriminated coarse orientation of static nonflickering Gabor patches. Spatial frequency was varied between 0.34 and $8.5 \mathrm{cycles} /{ }^{\circ}$, while temporal frequency was held constant at $0 \mathrm{~Hz}$.

Task 7 assessed coarse orientation discrimination of highly visible stimuli by measuring percentage correct performance for discriminating the orientation of high-contrast (Michelson contrast, 95\%) static nonflickering (temporal frequency, $0 \mathrm{~Hz}$ ) Gabor stimuli (spatial frequency, 1 cycle $\left.{ }^{\circ}\right)$.

Task 8 measured contrast thresholds for discriminating $90^{\circ}$ orientation differences around the horizontal axis $\left(0^{\circ}\right)$, as well as three untrained oblique axes $\left(30,45\right.$, and $\left.60^{\circ}\right)$. As for Task 3 , this task was only used after training to assess transfer of learning to untrained orientation axes.

Fine direction and orientation difference tasks. We used a same-different task, as shown in Figure $6 A, B$, in conjunction with the method of constant stimuli, to measure fine global direction difference thresholds (Task 9) and orientation difference thresholds (Task 10). In both tasks, a sample stimulus was presented in the first interval, lasting for $500 \mathrm{~ms}$, followed by a $100 \mathrm{~ms}$ delay. A test stimulus was then presented for $500 \mathrm{~ms}$ and subjects had to indicate by means of a button press whether the sample and the test stimuli were the same or different. This was repeated 
A Group 1: Static orientation training only

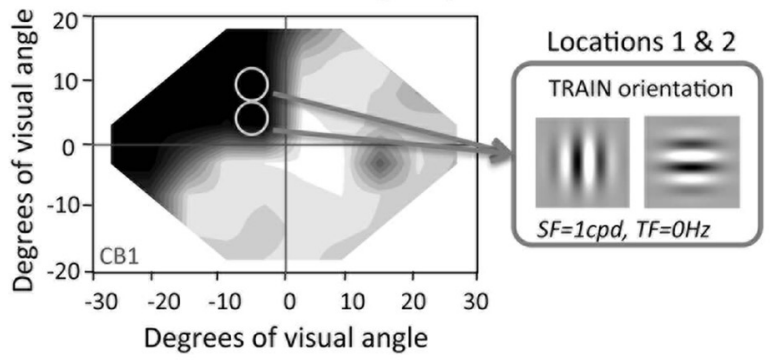

B Group 2: Orientation \& direction training

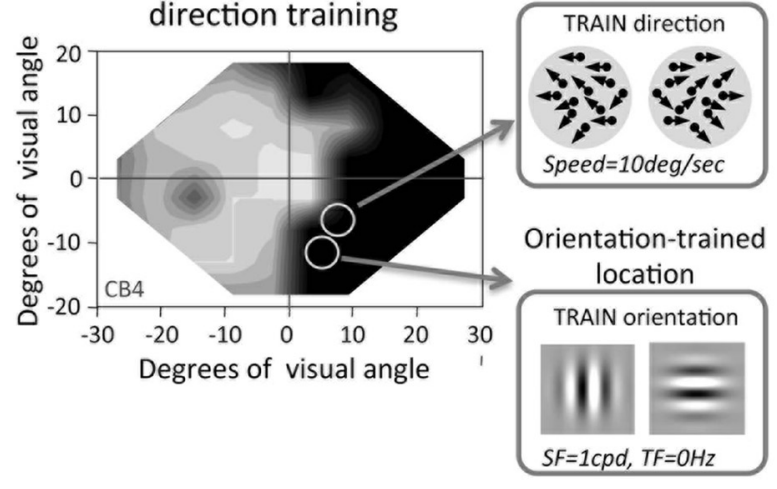

C

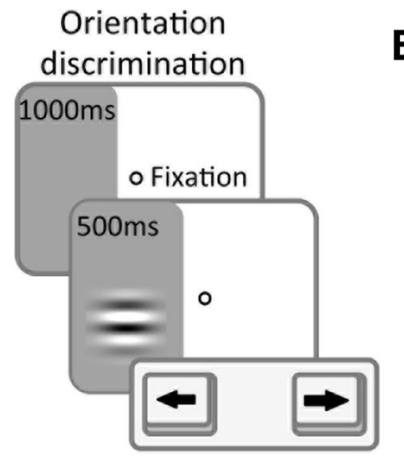

Vertical or Horizontal
E

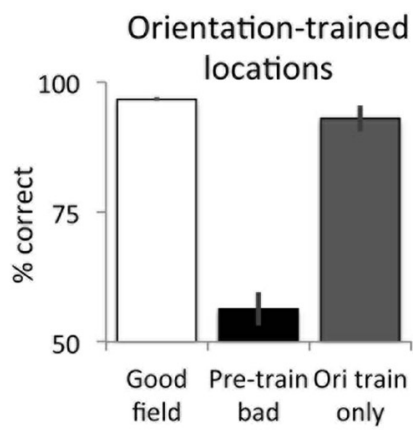

$\mathbf{F}$


Left or Right

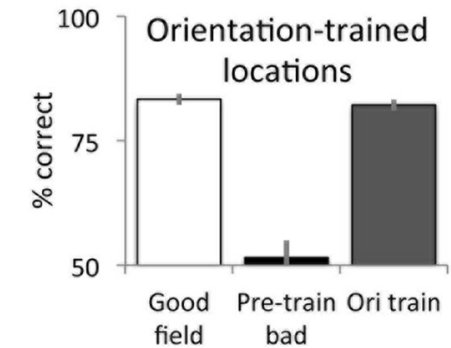

Figure 2. Behavioral paradigms and performance on trained tasks. $A$, Group 1 subjects were trained on a static vertical-horizontal orientation discrimination task with nonflickering [temporal frequency (TF) of $\mathrm{OHz}$, low spatial frequency (SF) Gabors. The size of the stimuli and training locations used in subject CB1 are indicated by circles on the subject's Humphrey visual field composite. $B$, Group 2 subjects were trained with two different tasks, at two locations in their blind field. One location was trained only on a global left-right direction discrimination task with random dot stimuli in which the range of dot directions was progressively increased during each training session. A second blind-field location was trained on only the same orientation discrimination task as Group 1 subjects (as described in $A$ ). The size of the stimuli and training locations used in subject (B4 are indicated by circles on the subject's Humphrey visual-field composite. C, Trial sequence for the static orientation discrimination task. Subjects were required to precisely fixate a centrally placed target on a computer monitor in front of them for $1000 \mathrm{~ms}$. A Gabor patch then appeared at a selected location for $500 \mathrm{~ms}$. Subjects were required to maintain fixation on the central target during stimulus presentation. After $500 \mathrm{~ms}$, the stimulus and fixation target disappeared and subjects were required to press to the right arrow key if they perceived a horizontal Gabor, or the left arrow key if they perceived a vertical Gabor. This was immediately followed by auditory response feedback. D, Trial sequence for the global direction discrimination task. Methods were identical to static orientation task, except a moving random dot stimulus was presented at a selected location. Subjects were required to press to the right arrow key if they perceived motion to the right, or the left arrow key if they perceived motion to the left. This was immediately followed by auditory response feedback. $\boldsymbol{E}$, Plot of mean percentage-correct performance \pm SEM for subjects in Group 1 when they were asked to perform Task 7 in their intact hemifield of vision (white bar, Good field), the chosen blind-field locations before the onset of training (black bar, Pretrain bad) and the same blind-field locations after orientation training (dark gray bar, Ori train only). $\boldsymbol{F}$, Plots of mean percentagecorrect performance \pm SEM in Group 2 subjects performing global direction discrimination or static orientation discrimination tasks in their intact hemifield of vision (white bars, Good field), the chosen blind-field locations before the onset of training (black bars, Pretrain bad) and the same blind-field locations after either direction training (light gray bar, DR train) or orientation training (dark gray bar, Ori train). Note that percentage-correct performance for both tasks was collected during testing with a staircase procedure, so that maximal performance averaged $\sim 82 \%$ correct.

Table 2. Impact of training on task performance in cortically blind fields

\begin{tabular}{|c|c|c|c|c|c|c|c|c|c|}
\hline & \multirow[b]{2}{*}{ Training } & \multicolumn{5}{|c|}{ Motion perception tasks } & \multicolumn{3}{|c|}{ Static perception tasks } \\
\hline & & $\begin{array}{l}\text { Tasks 1,3 } \\
\text { Direction } \\
\text { integration }\end{array}$ & $\begin{array}{l}\text { Task } 2 \\
\text { Motion } \\
\text { coherence }\end{array}$ & $\begin{array}{l}\text { Task } 4 \\
\text { Spatiotemporal } \\
\text { contrast } \\
\text { sensitivity }\end{array}$ & $\begin{array}{l}\text { Task } 5 \\
\text { Simple } 180^{\circ} \\
\text { direction } \\
\text { discrimination }\end{array}$ & $\begin{array}{l}\text { Task } 9 \\
\text { Fine gobal } \\
\text { direction } \\
\text { discrimination }\end{array}$ & $\begin{array}{l}\text { Task } 6 \\
\text { Contrast } \\
\text { sensitivity }\end{array}$ & $\begin{array}{l}\text { Tasks 7, } 8 \\
\text { Simple } 90^{\circ} \\
\text { orientation } \\
\text { discrimination }\end{array}$ & $\begin{array}{l}\text { Task } 10 \\
\text { Fine orientation } \\
\text { discrimination }\end{array}$ \\
\hline $\begin{array}{l}\text { Group 1: static training only } \\
\text { Group 2: double training }\end{array}$ & $\begin{array}{l}\text { Successful } \\
\text { Successful }\end{array}$ & $\stackrel{\theta}{0}^{*}$ & $\stackrel{\theta}{0}^{*}$ & a & $0^{*}$ & Not tested & a & $\mathbf{0}^{*}$ & 1 \\
\hline
\end{tabular}

, Full recovery; , partial recovery; $Q$, no or minimal recovery; ${ }^{*}$, tasks tested during pretraining assessments.

for a range of orientation and direction differences using a staircase procedure that enabled us to estimate difference thresholds.

We used relatively short interstimulus intervals (ISIs) in our samedifferent tasks (100 ms) to avoid confounding our results with possible deficits in visual working memory in CB subjects. We note, however, that because the oriented Gabor stimuli had gradual temporal onsets and offsets (raised cosine), the effective ISI was longer than $100 \mathrm{~ms}$ (e.g., the time difference between peak contrasts of each stimulus was $600 \mathrm{~ms}$, and 
the difference between half-maxima of each stimulus was $350 \mathrm{~ms}$ ). This both minimized backward masking effects and apparent rotation (which we subjectively confirmed by examining the stimuli). With respect to the motion stimuli, backward masking was also limited by the relatively long stimulus duration $(500 \mathrm{~ms})$ and the fact that coherent dot motion was used (backward masking usually occurs for brief stimuli that are quickly followed by a mask).

Threshold measurements. Staircase procedures were used to measure contrast, coherence and direction range, and difference thresholds. For each, the stimulus set was varied along a selected dimension (luminance contrast for sine wave gratings and Gabors, motion coherence, range of dot directions for random dot stimuli, orientation and direction differences), from the easiest to the most difficult. Three consecutive correct responses caused an increase in stimulus difficulty (i.e., reduced contrast, decreased proportion of signal dots, increased range of dot directions, decreased orientation and direction differences) while a single incorrect response decreased difficulty. Thresholds were calculated by fitting a Weibull function to the percentage correct performance at each stimulus level (luminance contrast, direction range, motion coherence, direction and orientation difference). The threshold criterion was $75 \%$ correct performance in all cases. Threshold luminance contrast was further converted to contrast sensitivity by calculating its inverse and multiplying it by 100 . Direction range thresholds were converted to NDR as detailed above.

\section{Visual training in cortically blind fields}

Subjects were assigned to one of two groups for training.

Group 1 -single training on static orientation discrimination. Three subjects (CB1-CB3) took part in this experiment to determine whether it was possible to retrain static orientation discrimination de novo in cortically blind fields. Before training, the borders of their blind/good field were mapped using a coarse orientation discrimination task with highcontrast Gabors $\left(1 \mathrm{cycle} /{ }^{\circ}, 95 \%\right.$ contrast). They were then trained at two nonoverlapping blind-field locations (Fig. $2 A$ ) on a coarse (vertical vs horizontal) orientation discrimination with high-contrast Gabors, as detailed above (Fig. 2C). To avoid performance improvements that could result from exposure during testing (Xiao et al., 2008; Zhang JY et al., 2010; Zhang T et al., 2010), they were not exposed to moving stimuli, or to Gabors of different spatial and temporal frequencies, until posttraining tests were performed.

$\mathrm{CB} 1$ trained in the laboratory, with fixation continuously monitored using an ISCAN eye-tracker. CB2 trained at home on a personal computer, but had her training performance verified in the laboratory at the end of training to ensure that improvements were not due to fixation breaks. CB3 trained $4 \mathrm{~d}$ /week at home and $1 \mathrm{~d}$ /week in the laboratory with controlled fixation. Because of the limited generalization of static training to untrained discriminations (see Results), only three subjects were trained using this paradigm.

After training, subjects in Group 1 underwent a battery of tests with the tasks listed above to assess both their learning on the trained task and the transfer of learning to untrained tasks and stimuli.

Group 2-double training on static and motion discrimination tasks. Before training, subjects CB4-CB9 had their borders mapped with the global direction discrimination task to identify $\geq 2$ blind-field locations where performance was at chance and where training would be conducted. Pretraining measures were then collected on Tasks 1-7 at both training locations. Each of the two blind-field locations was randomly assigned to either global direction discrimination training or static orientation discrimination training (Fig. 2B). The global direction discrimination stimuli and task used for training were identical to those used by Huxlin et al. (2009). In brief, subjects had to discriminate the left or right global direction of motion inside a random dot stimulus in which dots moved with a specified range of directions around the main directional axis. A direction range threshold was obtained from each training session. The static orientation discrimination task was the same task used in Group 1 training.

Subject CB4 trained in the laboratory on the same stimulus presentation computer used for pretraining and post-training tests, and with his fixation monitored using the infrared ISCAN eye tracker. All other sub- jects in Group 2 trained at home on a personal computer with an uncalibrated monitor using a background set at midgray. They used a chinforehead-rest system provided to them, which allowed their eyes to be positioned $42 \mathrm{~cm}$ away from the computer monitor presenting the visual stimuli, just as in the laboratory.

Post-training performance in Group 2 subjects was assessed using the complete battery of Tasks 1-10 to determine their learning on the trained task, as well as transfer of learning to untrained tasks and stimuli.

Training regimen. All subjects were required to perform one training session at each of their training locations for $\geq 5 \mathrm{~d}$ per week. Training sessions always comprised 300 trials and involved repeatedly discriminating the same stimulus type, i.e., either static Gabors or random dots. Stimulus types were never interleaved during a training session. Subjects were instructed to do one 300-trial-long training session in one sitting, with short breaks only if necessary. This was usually followed by a longer break to prevent fatigue, at which point subjects performed their second training session of the day in a different blind-field location (Fig. 2).

The average eccentricity for global direction discrimination training was $10 \pm 2.7^{\circ}$ and the average eccentricity for orientation discrimination training was comparable at $11 \pm 3.3^{\circ}$. It was impossible to precisely match eccentricities across subjects due to large differences in the topography of each person's blind field (Fig. 1). Performance at corresponding isoeccentric locations in the intact hemifields of vision (labeled "Good field" in all figures) was always measured as an internal control for each subjects' ability to understand and perform the tasks required of them. Good field thresholds were relatively normal, similar to those reported in the literature using comparable stimuli and tasks.

Training, although always fully in the blind field, commenced close to the blind-field border. As subjects improved and reached stability at each training location, the stimulus was moved deeper (i.e., away from the vertical meridian) into the blind field, by $1^{\circ}$ of visual angle. The criterion for considering someone fully retrained at a given blind-field location for the direction discrimination task was the subject maintaining performance $>75 \%$ correct and direction range thresholds equivalent to the isoeccentric good field location for $\geq 5$ consecutive sessions. The criterion for considering someone fully retrained at a given blind-field location for the static orientation discrimination task was $>80 \%$ correct performance $\geq 5$ consecutive training sessions. This process was repeated until subjects improved at a location that was $\geq 2^{\circ}$ deeper into the blind field than the original trained location. At this point, all subjects were brought back into the laboratory and post-training measurements were obtained with controlled fixation on the same apparatus and in a manner identical to that in which pretraining measurements were collected.

\section{Statistical methods}

For measures other than those included in the contrast sensitivity functions (CSFs), the mean and SD of the parameters of interest were compared between locations in the intact and blind fields, and as a function of training, with ANOVA tests. Post hoc Tukey's HSD tests were performed where necessary. To analyze contrast sensitivity curves, data were fit with a log-parabola CSF (Watson and Ahumada, 2005), adjusted for peripheral vision by eliminating the low spatial frequency truncation. This resulted in three parameters: peak sensitivity, peak spatial frequency, and bandwidth of the CSF. Statistical significance in the CSFs was assessed by nonparametric bootstrap analysis with 10,000 correlated pretraining and post-training samples to account for the repeated-measures training design (when comparing across different groups of subjects, samples were independent).

\section{Results}

\section{Static orientation discrimination can be retrained de novo in cortically blind fields}

Group 1 subjects (CB1-CB3) were only exposed to and trained with static nonflickering high-contrast low spatial frequency Gabors (Task 7). No moving stimuli were used during pretraining tests. Baseline percentage correct performance for coarse (verti$\mathrm{cal} /$ horizontal) static orientation discrimination at the blindfield locations selected for training was $56 \pm 6 \%$ (mean $\pm \mathrm{SD}$ ), 

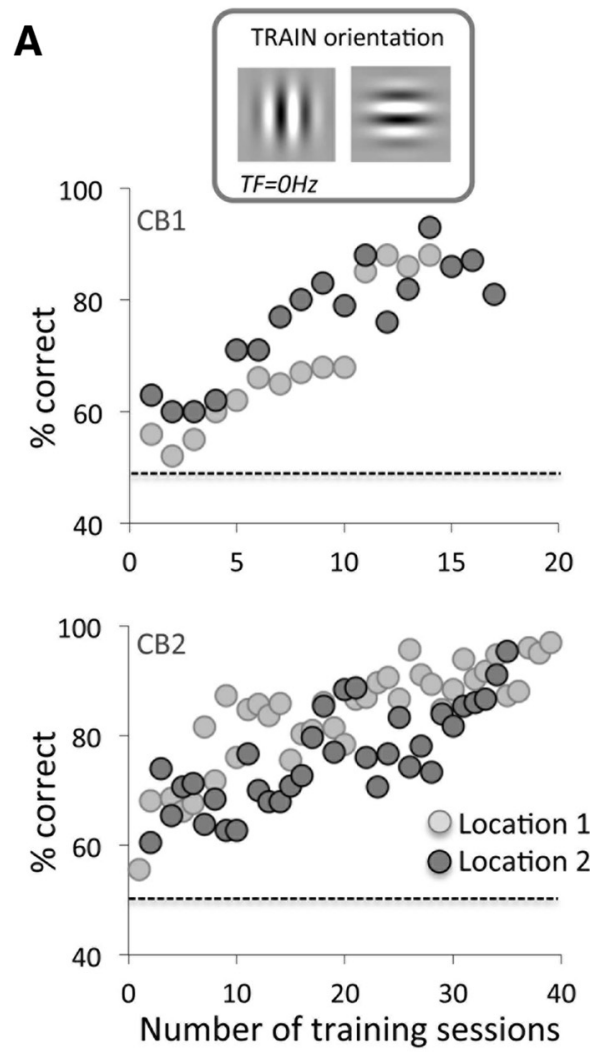

B

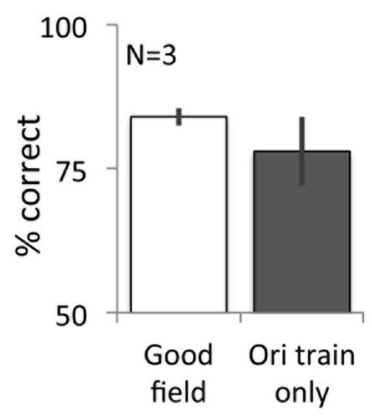

C



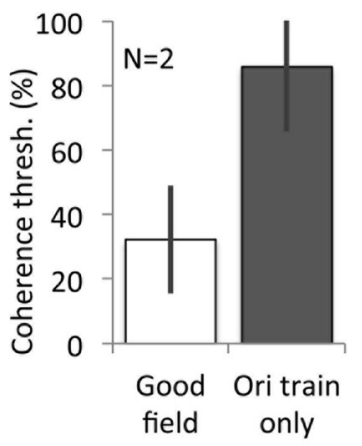

Figure 3. Impact of training in Group 1 (single-trained) subjects. $\boldsymbol{A}$, Percentage-correct performance across consecutive training sessions at two blind-field locations trained on orientation discrimination in CB1 and CB2. For CB1, these two locations are indicated by circles on the Humphrey field composite in Figure $2 A$. Both subjects showed improvement as a function of the number of training sessions, which was similar at their two trained locations. The dotted lines indicate chance performance on this task ( $50 \%$ correct). TF, Temporal frequency. $\boldsymbol{B}$, Mean percentage-correct performance ( \pm SEM) for subjects in Group 1 when performing a simple direction discrimination task with high-contrast, drifting gratings after training. Post-training performance at blind-field locations trained only on the static orientation discrimination task (Ori train only) were not significantly different from that in their intact hemifield of vision (Good field; see text for statistics). $\boldsymbol{C}$, Mean coherence and DR thresholds ( \pm SEM) for subjects in Group 1 following orientation training only. Post-training thresholds at blind-field locations trained only on the static orientation discrimination task (Ori train only) were significantly worse than thresholds in the same subjects' intact hemifields of vision (Good field). Data for $\boldsymbol{B}$ and $\boldsymbol{C}$ were collected in the laboratory with controlled fixation.

which was close to chance (Fig. $2 E$ ). Though learning was faster in $\mathrm{CB} 1$ and $\mathrm{CB} 3$ than in $\mathrm{CB} 2$ (Fig. $3 A$ ), all three subjects successfully relearned to discriminate orientation of static Gabors at their trained blind-field locations (Fig. 2E). For CB1, these two locations are indicated in Figure $2 A$. Following training, percentage correct performance improved to $\sim 90 \%$ correct (Fig. $2 E$, gray bar), which was similar to performance at corresponding locations in the subjects' intact hemifields of vision (Fig. $2 E$, white bar). A repeated-measures ANOVA revealed a main effect of location (good field, bad field pretraining, bad field post-training) on performance $\left(F_{(2,4)}=137.75, p=0.00021\right)$. Post hoc Tukey's HSD tests verified that pretraining bad field performance was significantly poorer than that in the good field, and than at the post-training DR-trained and orientation-trained blind-field locations. There were no significant differences between good field performance and post-training bad field performance. This is a notable result because it shows that cortically blind subjects can learn to discriminate stimuli outside of the spatiotemporal bandwidth of blindsight.

Surprisingly, these three subjects also showed the ability to discriminate left/right directions of motion when tested with drifting sine wave gratings (Task 5; Fig. 3B). This transfer to motion was unexpected because $\mathrm{CB}$ subjects are normally unable to perform these discriminations in their blind field (Huxlin et al., 2009) and Group 1 subjects were not exposed to moving or flickering stimuli until the post-training tests were administered. However, it should be noted that because of our aim not to ex- pose Group 1 subjects to moving stimuli during pretraining, we cannot say with absolute certainty that Group 1 subjects could not reliably discriminate complex moving stimuli before training. Nevertheless, it is highly unlikely that Group 1 subjects were able, if tested during pretraining, to discriminate complex motion. We reported on seven CB subjects in Huxlin et al., (2009) and an additional six subjects in the present study, and all of these subjects performed at chance levels before the onset of training on complex motion discrimination tasks. This conclusion is also consistent with other studies (Azzopardi and Cowey, 2001). Going back to the present results, percentage correct performance for direction discrimination at static-trained blind-field locations was not significantly different from that measured in the same subjects' intact hemifield of vision (two-tailed paired Student's $t$ test: $t_{2}=1.33, p=0.31$ ). While Group 1's small sample size limited our ability to find statistical differences between good field and post-training bad field performance, it is clear that for both simple orientation and motion direction discrimination, training with static stimuli was sufficient for performance to recover to levels that were comparable to the good field.

Given that Group 1 subjects recovered simple motion discrimination at their static orientation-trained blind-field locations, we then asked whether such training also induced recovery of more complex motion discrimination (Tasks 1 and 2). All three subjects were able to discriminate motion direction of random dot stimuli above chance at the orientation-trained locations, but direction range thresholds averaged $( \pm$ SD) $72 \pm 28 \%$, 




Number of training sessions

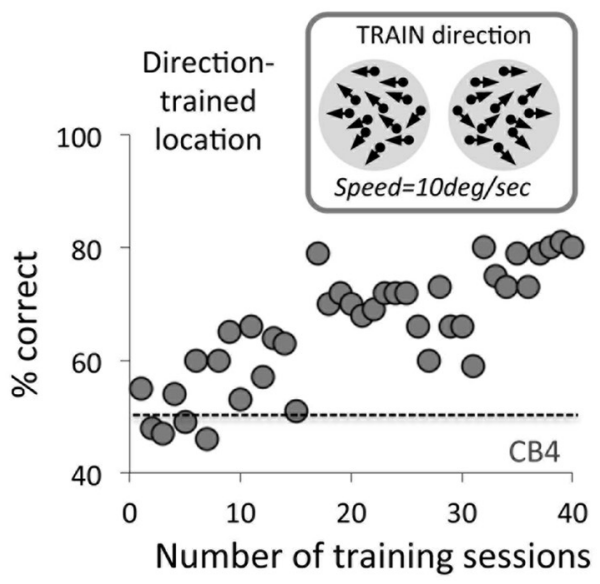

B

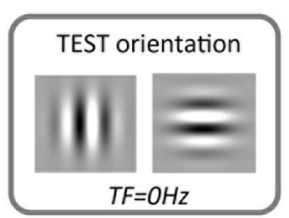

C

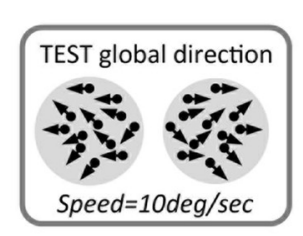

D

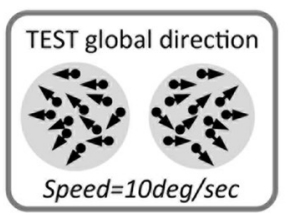

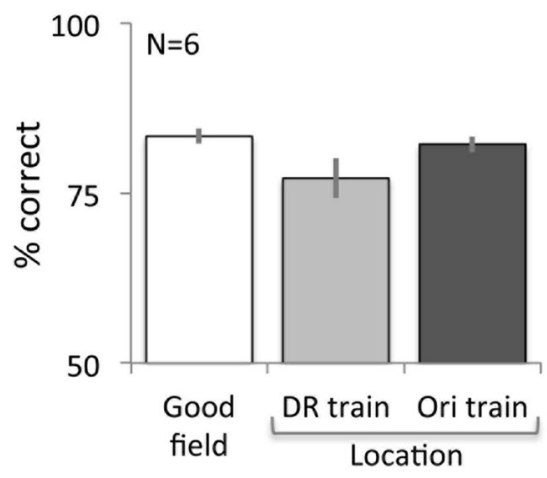
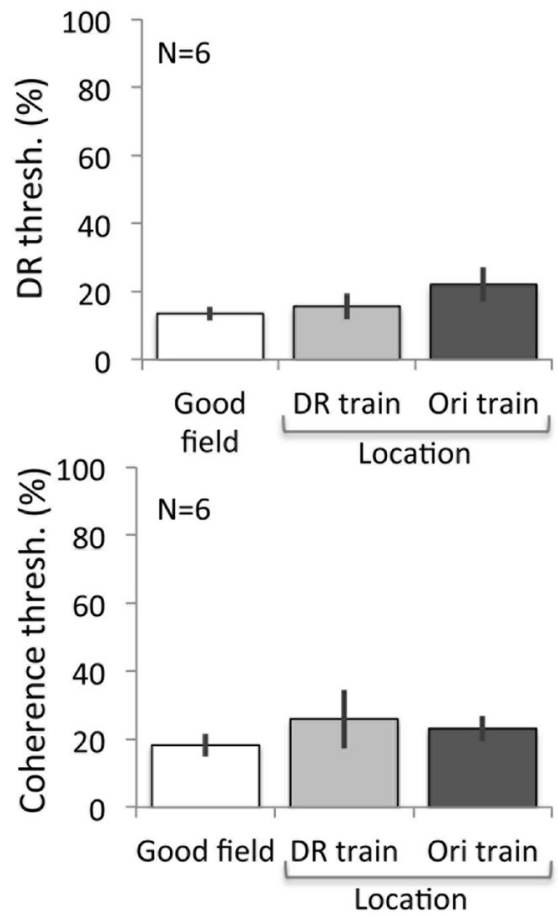

Figure 4. Impact of training in Group 2 (double-trained) subjects. $A$, Percentage correct performance for CB4 across consecutive training sessions at one blind-field location trained on static orientation discrimination (upper graph) and one blind-field location trained with a global direction discrimination task (bottom graph). These two locations are indicated by circles on CB4's Humphrey field composite in Figure $2 B$. Improvement as a function of the number of training sessions can be seen at both trained locations. The dotted lines indicate chance performance on this task $(50 \%$ correct). TF, Temporal frequency. $\boldsymbol{B}$, Mean percentage-correct performance $( \pm \mathrm{SEM})$ for the six subjects in Group 2 when doing a static orientation discrimination task in their intact hemifield of vision (white bars, Good field), blind-field locations where they were trained with the DR task (light gray bars, DR train) and blind-field locations trained on the static orientation discrimination task (dark gray bars, Ori train). Note that percentage-correct performance improves from approximately chance (Fig. 2F) to levels not significantly different from good field levels following both types of training (see text for statistics). C, DR thresholds ( \pm SEM) for the six subjects in Group 2 when performing a global left-right direction discrimination task either in their intact hemifield of vision (Good field) or at blind-field locations trained either on DR (DR train) or static orientation discrimination (Ori train). Post-training performance at retrained blind-field locations was not significantly different from that in the intact hemifield of vision. $D$, Mean coherence thresholds ( \pm SEM) for the six subjects in Group 2 following double training. As for DR thresholds, post-training coherence thresholds were not significantly different from those in the same subjects' intact hemifields of vision. Data for $\boldsymbol{B}-\boldsymbol{D}$ were collected in the laboratory with controlled fixation.

$\sim 3$ times worse than in the same subjects' intact hemifield of vision $(23 \pm 2 \%$; Fig. $3 C)$. Mean coherence threshold was $85 \pm$ $20 \%$ at these same orientation-trained blind-field locations, four times worse than thresholds obtained in the same subjects' intact hemifield of vision $(22 \pm 11 \%$, Fig. $3 C)$. Evidently, training with static stimuli recovered subjects ability to perform simple motion discrimination of high-contrast moving gratings, but the ability to perceive complex motion showed only partial recovery.

\section{Double training with static and moving stimuli cross-trains} different blind-field locations

Group 2 subjects (CB4-CB9) were double-trained in the sense that every day they trained on a global direction discrimination task (Task 1) at one blind-field location for a whole 300-trial session, followed (or preceded) by training on a static orientation discrimination task (Task 7) at a second blind-field location for another 300-trial session. Before onset of training, these subjects were exposed to both moving and static stimuli at each of the blind-field locations selected for training. Across these six subjects, baseline percentage correct performance (mean $\pm S D$ ) for global direction discrimination at locations destined for static orientation training was $55 \pm 14 \%$, while at locations destined for global direction discrimination training, it was $50 \pm 8 \%$ (Fig. $2 F$ ). Baseline percentage correct performance for static orientation discrimination at these same locations was $52 \pm 9 \%$ and $50 \pm 4 \%$, respectively (Fig. $2 F$ ).

As shown in Figures $2 F$ and $4 A$, subjects improved on both types of tasks at both trained blind-field locations. Moreover, both forms of training improved orientation discrimination of static nonflickering Gabors (Task 7) to a percentage-correct level not significantly 


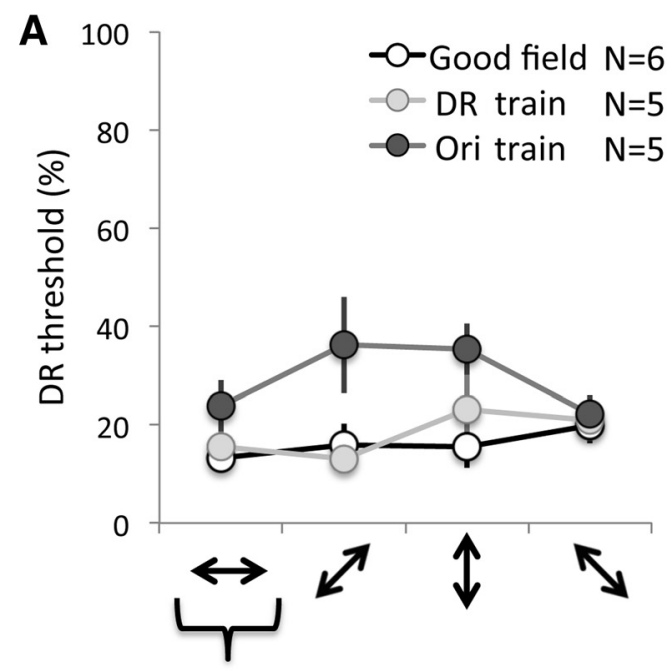

Trained direction



Trained

orientation

Figure 5. Transfer of learning to untrained direction and orientation axes. $\boldsymbol{A}$, Comparison plot of post-training DR thresholds for coarse direction discrimination (180 ${ }^{\circ}$ direction difference) across four different directional axes (oriented arrows). Data are mean thresholds ( \pm SEM) computed separately in the intacthemifield of vision (white dots, Good field), as well as at direction-trained (light gray dots, DR train) and orientation-trained (dark gray dots, Ori train) locations in the blind field of six double-trained CB subjects. Group 1 subjects did not provide reliable DR thresholds after training (Fig. 3C) and were thus not used in this task. In addition, among Group 2 subjects, post-training blind-field data were not collected for the direction-trained location in CB4 and the orientation-trained location in (B3. Statistical analysis (see text for details) revealed a lack of significant difference between performance at the trained and untrained axes of motion. $\boldsymbol{B}$, Comparison plot of post-training luminance contrast thresholds for coarse orientation discrimination ( $90^{\circ}$ direction difference) across four different orientation axes (indicated by oriented bars). Data are mean thresholds ( \pm SEM) computed separately in the intact hemifield of vision as well as at direction-trained and orientation-trained locations in the blind field of five double-trained and two single-trained subjects. Labeling conventions are as in $\boldsymbol{A}$. Among Group 2 subjects, post-training blind-field data were only collected in three of five subjects for the direction-trained location. Statistical analysis (see text for details) revealed a lack of significant difference between performance at the trained and untrained orientation axes, regardless of visual-field location tested. However, note that contrast thresholds were significantly worse in the trained blind-field locations relative to good field values. This contrast sensitivity deficit after training is further detailed in Figure 7. Data for this figure were collected in the laboratory with controlled fixation.

different from good field values (Fig. 4B). A repeated-measures ANOVA revealed a main effect of location (good field, bad field pretraining, DR-trained and orientation-trained locations) on performance $\left(F_{(3,15)}=63.51, p<0.0001\right)$. Post hoc Tukey's HSD tests verified that pretraining bad field performance was significantly poorer than that in the good field and those at the post-training DR-trained and orientation-trained blind-field locations. There were no significant differences between good field performance and post-training bad field performance.

However, there was one striking difference from Group 1 results: in Group 2 subjects, direction range (Task 1) and coherence thresholds (Task 2) recovered to levels comparable to those measured in the same subjects' good fields at both DR-trained and static orientation-trained locations (Fig. 4C,D; DR thresholds, $F_{(2,15)}=$ $0.16, p=0.85$; coherence thresholds, $\left.F_{(2,15)}=0.47, p=0.63\right)$.

\section{Discrimination training generalizes to untrained direction and orientation axes}

An interesting question in the context of the directiondiscrimination and orientation-discrimination training administered to CB subjects was whether recovery of seemingly normal performance elicited at the trained locations was restricted to the trained direction and orientation axes. To answer this question, we assessed performance for untrained directions/orientations using direction-range thresholds (for direction discrimination, Task 3 ) and contrast thresholds (for orientation discrimination, Task 8 ) in a proportion of subjects at both the trained blind-field locations and the corresponding locations in the "good" hemifield of vision. Data from Group 1 was included in the contrastthreshold analysis, but not in the direction-range analysis, since Group 1 subjects had normal orientation discrimination perfor- mance but very poor complex motion thresholds (Fig. 3). As can be seen from Figure $5 A$, double-trained subjects exhibited similar direction-range thresholds at all direction axes tested, whether trained $\left(0^{\circ}\right)$ or untrained $\left(45,135\right.$, and $\left.90^{\circ}\right)$. A two-way ANOVA with visual field location (good field, motion-trained, orientation-trained) as the between-subject factor and motion axis $\left(0,45,90,135^{\circ}\right)$ as the within-subject factor revealed no significant effect of axis $\left(F_{(3,39)}=1.12, p=0.35\right)$ and no significant interaction between location and axis $\left(F_{(6,39)}=1.292, p=\right.$ $0.28)$, though there was an overall main effect of location $\left(F_{(2,13)}\right.$ $=5.326, p=0.02)$. In contrast, locations trained on the global direction discrimination task exhibited direction-range thresholds that were similar to good field values for both trained and untrained directional axes.

With respect to discrimination of trained orientations (horizontal vs vertical), contrast thresholds obtained by subjects who performed Task 8 in Groups 1 and 2 were similar, with mean \pm SD contrast threshold at orientation-trained locations of $32 \pm$ $13 \%$ for Group 1 subjects $(N=2)$ and $25 \pm 19 \%$ for Group 2 subjects $(N=5)$. Therefore, we combined data from all orientation-trained subjects in subsequent analyses. As can be seen from Figure $5 B$, subjects exhibited similar contrast thresholds at all orientations tested, whether trained (base orientation, $0^{\circ}$ ) or untrained (base orientation, 30, 45, or $60^{\circ}$ ). A two-way ANOVA with visual field location (good field, motion-trained, orientation-trained) as the between-subject factor and orientation axis $\left(0,30,45,60^{\circ}\right)$ as the within-subject factor revealed no significant effect of axis $\left(F_{(3,42)}=1.36, p=0.27\right)$ and no significant interaction between location and axis $\left(F_{(6,42)}=1.376, p=\right.$ $0.25)$, although there was a main effect of location $\left(F_{(2,14)}=\right.$ $14.81, p=0.0004)$. 
A

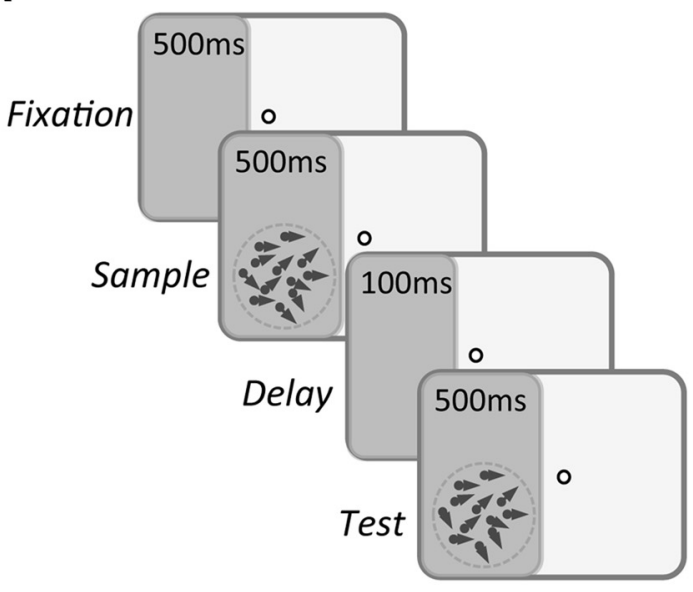

B

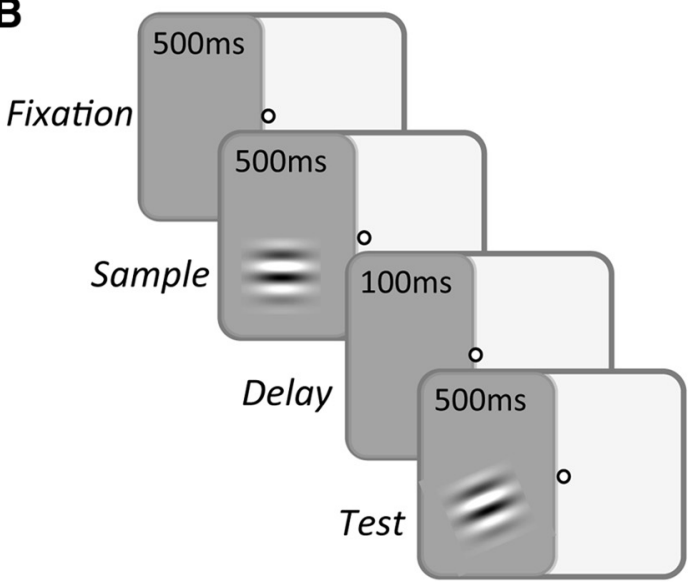



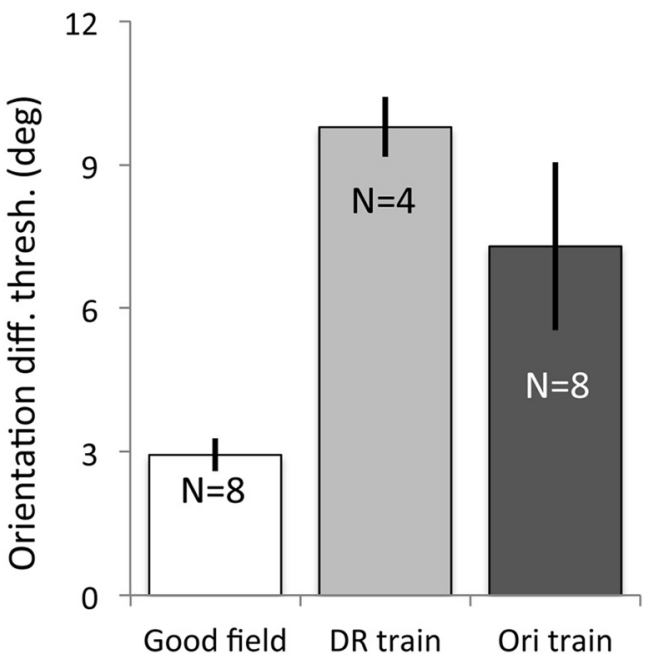

Figure 6. Effects of coarse discrimination training on fine difference thresholds. $A$, Schematic of the same- different trial sequence used to measure direction difference thresholds using random dot stimuli in post-training CB subjects (left). Comparison plot (right) of post-training direction difference thresholds (mean \pm SEM) in the intact hemifield of vision (white bar, Good field), and at the direction-trained (light gray bar, DR train) and orientation-trained (dark gray bar, Ori train) blind-field locations. Group 1 subjects were not tested on this task because of their difficulty in discriminating global motion direction (Fig. 3C. There was a significant impairment in difference thresholds at both direction-trained and orientation-trained blind-field locations, relative to the good field. B, Schematic of the same-different trial sequence used to measure orientation difference thresholds using static Gabors in post-training CB subjects (left). Comparison plot (right) of post-training direction difference thresholds (mean \pm SEM) in the intact hemifield of vision (white bar, Good field), and at the direction-trained (light gray bar, DR train) and orientation-trained (dark gray bar, Ori train) blind-field locations. Data from Groups 1 and 2 are combined for this graph. There was a significant impairment in orientation difference thresholds at both direction-trained and orientation-trained blind-field locations, relative to the good field. Data for this figure were collected in the laboratory with controlled fixation.

\section{Coarse discrimination training improves fine discrimination thresholds}

Before the onset of training, none of the subjects could discriminate global motion direction or static orientation sufficiently reliably to collect direction and orientation difference thresholds (Tasks 9 and 10). After training, we avoided collecting these data in Group 1 subjects because of their poor global motion perception (directiondifference thresholds were measured using random dot stimuli, which were difficult for these subjects to discriminate). Directiondifference thresholds were measured in five of the Group 2 subjects (Fig. 6A). However, we were able to collect post-training orientationdifference thresholds in Group 1 subjects, as well as in five of the Group 2 subjects. Because these orientation data were not significantly different between groups, they were averaged together in Fig. $6 B$.

Around the trained direction axis, post-training directiondifference thresholds were significantly larger than good field values at both the DR-trained and orientation-trained blind-field locations
(Fig. 6A). A repeated-measures ANOVA revealed a main effect of location tested (good field, DR-trained and orientation-trained) on performance $\left(F_{(2,8)}=11.41, p=0.005\right)$. Post hoc Tukey's HSD tests verified that performance at the DR-trained and orientation-trained blind-field locations were significantly worse than in the good field (DR-trained: $p<0.01$; orientation-trained: $p<0.01$ ), but not significantly different from each other.

Similarly, post-training orientation-difference thresholds were significantly larger than good field values for both training conditions (Fig. 6B). A one-way ANOVA revealed a main effect of location tested (good field, DR-trained and orientation-trained) on performance $\left(F_{(2,17)}=6.78, p=0.007\right)$. Post hoc Tukey's HSD tests verified that performance at both DR-trained and orientation-trained blind-field locations was significantly worse than in the good field (DR-trained: $p<0.01$; orientation-trained: $p<0.01$ ), and there were no significant differences between DRtrained and orientation-trained locations. 


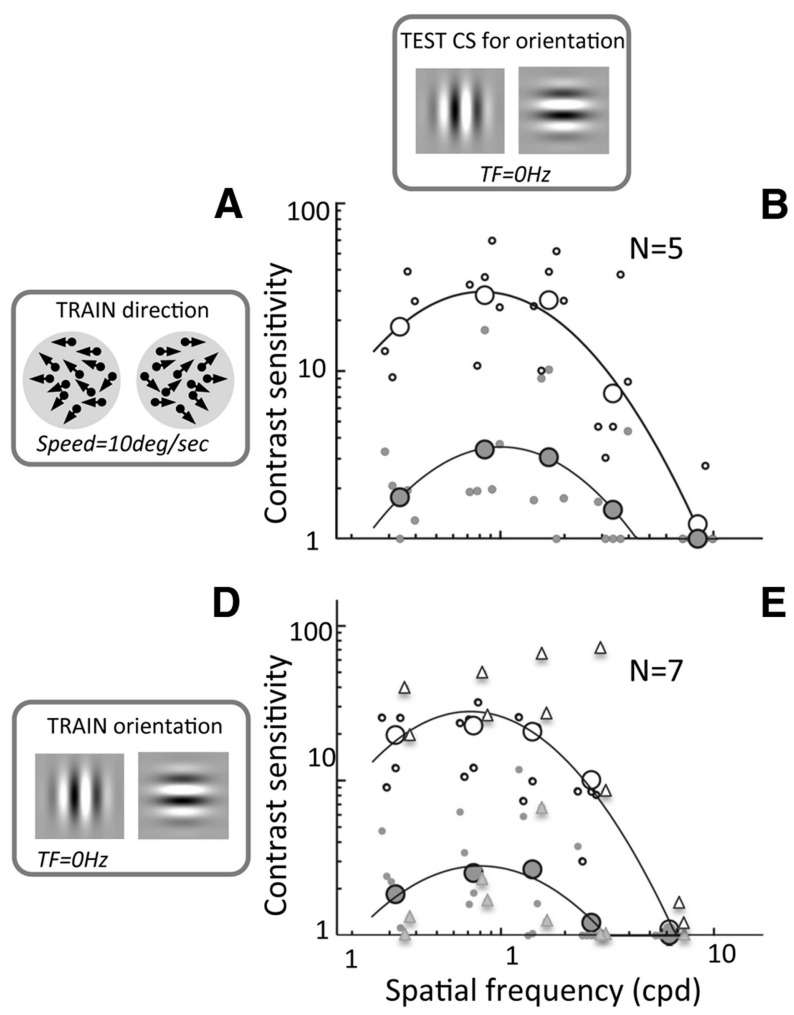

$\bigcirc$ Good field
Post-train bad field

B
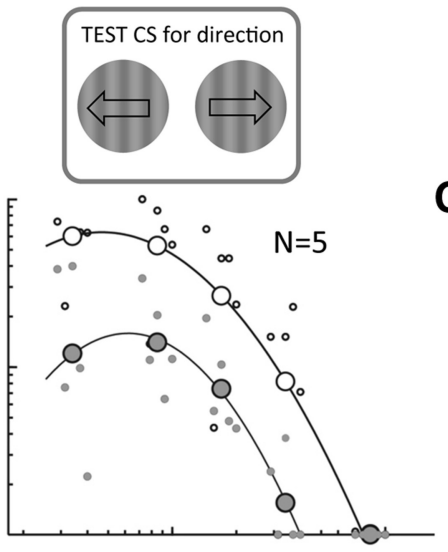

C

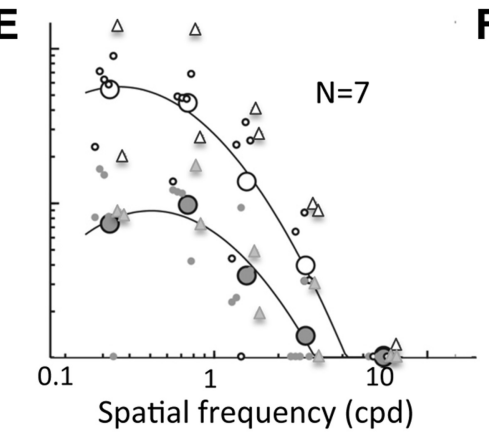

F
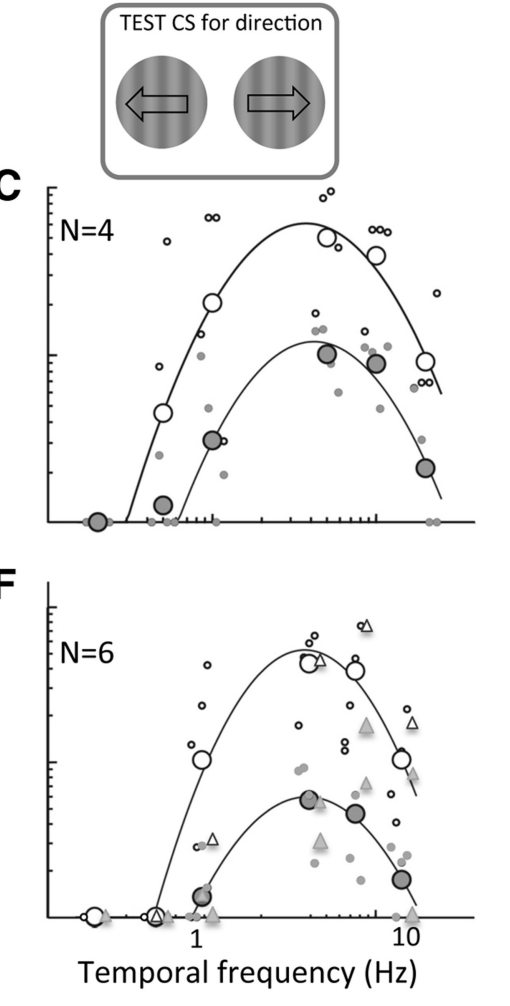

$\Delta$ Single trained subjects

o Double trained subjects 
in trained blind-field locations were significantly poorer than thresholds at corresponding good field locations (directiontraining locations, all $p<0.05$; orientation-training locations, all $p<0.016$ ), resulting in a significant gain difference between post-training and good field thresholds following both types of training (direction training, $p=0.0002$; orientation training, $p<$ $0.0001)$. However, there were no significant differences in bandwidth (direction training, $p=0.90$; orientation training, $p=$ 0.70 ) or peak frequency (direction training, $p=0.65$; orientation training, $p=0.88$ ). When comparing orientation-trained and dot-trained locations, there were also no significant differences in peak CSF sensitivity $(p=0.078)$, CSF bandwidth, $(p=0.97)$, and peak frequency $(p=0.24)$.

\section{CSFs for orientation discrimination (Task 6)}

Contrast sensitivity for orientation discrimination of static nonflickering Gabors improved sufficiently at both motion-trained and static-trained locations to generate reliable CSFs (Fig. 7C,F). However, just as for CSFs measured for direction discrimination, bootstrap analysis showed that contrast sensitivity at trained blind-field locations remained significantly lower than in the good field at all spatial frequencies for which thresholds could be measured (direction training, all $p<0.0008$; orientation training, all $p<0.004)$. Overall, the difference between good field and post-training bad field CSFs was significant only for the effect of gain (direction training, $p=0.0008$; orientation training, $p<$ 0.0001 ). Bandwidth (direction training, $p=0.82$; orientation training, $p=0.76$ ) and peak frequency (direction training, $p=0.46$; orientation training, $p=0.65$ ) were not significantly different. As for previous CSFs measured, when comparing orientation-trained and dot-trained locations, no significant differences in peak CSF sensitivity $(p=0.58)$, CSF bandwidth $(p=$ 0.79 ), and peak frequency ( $p=0.64$ ) were observed.

In summary, both types of training (global direction and static orientation discrimination) administered to CB fields, though they involved only high-contrast stimuli (moving random dots or static Gabors), induced partial improvements in contrast sensitivity for direction and orientation discrimination, with a broad-bandwidth across spatial and temporal frequencies.

\section{Discussion}

Visual perceptual learning (PL) refers to the ability of visual system to improve its perceptual performance following repeated visual training. A documented property of PL in visually intact adults is specificity for trained stimulus attributes and retinotopic location (Fiorentini and Berardi, 1980; Karni and Sagi, 1991; Sagi and Tanne, 1994; Schoups et al., 1995). The tight retinotopic and stimulus specificity of PL has been used to suggest that early retinotopic areas underlie learning (Schoups et al., 2001; Fahle and Poggio, 2002; Seitz and Watanabe, 2005; Sagi, 2011). However, manipulating the training procedure can reduce the specificity of learning. One such approach is to reduce the task difficulty (Ahissar and Hochstein, 1997) or to reduce the precision of the discrimination to be made (Jeter et al., 2009). Transfer of learning can also be facilitated by a double-training procedure in which different kinds of stimuli and locations are trained on interleaved blocks (Xiao et al., 2008; Zhang JY et al., 2010). As summarized in Table 2, we demonstrate for the first time that cortically blind subjects can (1) relearn to discriminate the orientation of static Gabors; and (2), when double-trained, show transfer of learning across tasks and trained blind-field locations. These findings give new insights into mechanisms of neural plas- ticity and the type of vision that can be recovered through training in the absence of an intact V1.

$\mathrm{CB}$ subjects are poor at discriminating direction for anything but the simplest targets (Weiskrantz et al., 1995; Azzopardi and Cowey, 2001; Huxlin et al., 2009). They are even worse at detecting and discriminating the orientation of small, static stimuli with temporal frequencies $<5 \mathrm{~Hz}$ (Sahraie et al., 2008). This was confirmed in the present cohort of CB subjects. However, training enabled the same subjects to relearn to discriminate global direction and static orientation at their trained blind-field locations.

The surprising result, though, was that $\mathrm{CB}$ subjects were able to relearn orientation discrimination of small (by blindsight standards), nonflickering, nonmoving Gabors with slow (250 ms) onsets and offsets in their blind fields. Group 1 results indicate that such relearning did not require prior or concurrent motiondiscrimination training in the blind field, suggesting that motionsensitive pathways, which are often invoked to explain blindsight, were not the main ones recruited here. Instead, learning may have relied on direct inputs from the dorsal LGN to V2, V3, and/or V4 (Cowey et al., 1989; Hendry and Reid, 2000; Schmid et al., 2010), cortical areas that are rich in orientation-selective units (Desimone and Schein, 1987; Gegenfurtner et al., 1996, 1997).

In addition to recovering orientation discrimination, training with static Gabors improved motion perception. In Group 1 subjects, this generalization only extended to the discrimination of simple, high-contrast gratings, while direction range and coherence thresholds remained severely impaired. This also supports the notion that training with simple Gabors likely stimulated different circuits than those recruited by complex motion training (Ahissar and Hochstein, 2004; Das et al., 2012). Specifically, orientation training may have recruited orientation-selective circuits in partially spared, early visual areas (Baseler et al., 1999; Goebel et al., 2001), which could have been used to discriminate simple motion, but not to integrate across directions or extract motion signal from noise.

In contrast, the ability to retrain global motion discriminations in CB fields is most easily explained as an extension of blindsight. In this condition, sensitivity to motion, luminance flux, or any sort of stimulus transient is generally taken to suggest mediation by inputs from the superior colliculus/pulvinar/dorsal LGN to MT, bypassing the damaged V1/early visual cortices (Rodman et al., 1989, 1990; Sincich et al., 2004; Berman and Wurtz, 2010, 2011; Leh et al., 2010; Tamietto et al., 2010). There is some experimental evidence suggesting that MT mediates residual motion sensitivity in blindsight (Alexander and Cowey, 2009), and that MT is necessary for learning of complex motion discrimination in visually intact subjects (Lu et al., 2004; Thompson and Liu, 2006). By extension, MT could mediate relearning of complex motion discrimination in CB fields.

The only condition when both orientation-selective and higher-level motion circuits appeared to have been recruited, and in which retinotopic specificity of learning seemed to break down, occurred in double-trained subjects (Group 2). These subjects exhibited transfer of learning to both simple and complex motion at blind-field locations trained on static orientation discrimination. Conversely, blind-field locations trained on a global direction discrimination task improved not only on the trained task, but also on coherence thresholds (Huxlin et al., 2009), and on several static orientation discriminations (coarse, fine, and contrast sensitivity). Improvements were still restricted to trained blind-field locations, but now there was crossover of learning between the two trained locations, even though they 
never overlapped and were often in different quadrants of the visual field. Thus, as reported in visually intact humans (Xiao et al., 2008; Zhang JY et al., 2010; Wang et al., 2012), double training can confer distinct advantages for generalization of learning in $\mathrm{CB}$. Although our training paradigm did not interleave orientation and direction trials, it is possible that the mutual relevancy of these two features (Wang et al., 2012), combined with broad effects of reinforcement, rule-based learning (Zhang JY et al., 2010), or even pretraining exposure during baseline testing, potentiated transfer of learning between orientation-trained and direction-trained locations in Group 2.

It could be argued that the transfer of learning between locations in Group 2 could be due to the pretraining tests in these subjects - either in the intact hemifield, or at the blind-field locations to be trained. Indeed, even brief pretesting can generalize orientation learning from a trained to an untrained location (Zhang T et al., 2010). Consistent with previous results (Huxlin et al., 2009; Sahraie et al., 2010a), untrained blind-field locations, even when directly adjacent to trained locations, required direct and prolonged training (10s of sessions, 300 trials each) before any improvements occurred. Since pretraining tests, either in the good or blind hemifields of vision, did not elicit detectable performance improvements in the blind field, it is unlikely that they could explain the observed transfer of learning seen in cortically blind fields.

Next, we found that coarse (left-right/horizontal-vertical) discrimination training generalized to untrained direction and orientation axes. For Group 2, this was unsurprising since the random dot stimuli used at one of their training locations contained a broad range of motion directions. Generalization to untrained orientations was harder to explain, especially in singletrained subjects (Group 1), who were never exposed to different orientations (or motion directions) during baseline tests or training. Perhaps in their case, low precision of the training task (Jeter et al., 2009) or rule-based learning mechanisms (Zhang JY et al., 2010) allowed generalization to occur. However, coarse discrimination training also improved fine orientation and direction discrimination. This indicated that subjects had not just learned to process aspects of the training stimulus necessary to perform the trained task, they also truly relearned how to discriminate orientation and direction.

CB subjects, regardless of training group, also showed improvements in contrast sensitivity at all trained blind-field locations. Interestingly, CSF improvements were spatiotemporally broadband. This was not unexpected following global motion training since random dot stimuli are relatively broadband, at least in the spatial frequency domain (Pasternak et al., 1995). However, orientation training only used 1 cycle $/{ }^{\circ}$ Gabors, with narrowband temporal frequency centered at $0.5 \mathrm{~Hz}$. Broadband CSF improvements were also obtained in amblyopic subjects following contrast training (Huang et al., 2008), while learning in normal observers tends to be narrower and centered on the trained spatial frequency (Sowden et al., 2002). Although other explanations have been offered, damaged or abnormally developed visual systems may well exhibit broader-than-normal transfer of learning.

Although significant improvements were attained by training, recovered vision in $\mathrm{CB}$ fields remained suboptimal. Post-training CSFs, direction-difference and orientation-difference thresholds were several-fold poorer than in the good field. These deficits likely reflect residual processing inefficiencies, which could either be permanent or amenable to further training. The lesion sustained by our subjects decreased the number of orientation- selective and direction-selective neurons in their visual system, and it has also been shown that visual cortex damage increases internal processing noise (Hayes and Merigan, 2007). Both factors can impair discrimination performance at lower stimulus contrasts (Pasternak and Leinen, 1986; Pasternak, 1990; Dosher and $\mathrm{Lu}, 1999)$. Although training may teach the system to overcome some of its processing deficits, it may ultimately be limited by the permanent loss of a critical portion of its circuitry.

In conclusion, the present experiments show for the first time that discrimination of stimuli not optimal for blindsight can be relearned by $\mathrm{CB}$ subjects, and that using complex stimuli in a double-training configuration maximizes generalization of learning across both location and task. However, we also report that recovered vision in $\mathrm{CB}$ fields is not normal, with persistent deficits in contrast sensitivity and fine discrimination abilities. Further studies are needed to reveal whether training targeted specifically at improving these deficits will be effective, or whether there are limits to the plasticity that can be invoked to recover vision without an intact primary visual cortex.

\section{References}

Ahissar M, Hochstein S (1997) Task difficulty and the specificity of perceptual learning. Nature 387:401-406. CrossRef Medline

Ahissar M, Hochstein S (2004) The reverse hierarchy theory of visual perceptual learning. Trends Cogn Sci 8:457-464. CrossRef Medline

Alexander I, Cowey A (2009) The cortical basis of global motion detection in blindsight. Exp Brain Res 192:407-411. CrossRef Medline

Azzopardi P, Cowey A (2001) Motion discrimination in cortically blind patients. Brain 124:30-46. CrossRef Medline

Barbur JL, Harlow AJ, Weiskrantz L (1994) Spatial and temporal response properties of residual vision in a case of hemianopia. Philos Trans R Soc Lond B Biol Sci 343:157-166. CrossRef Medline

Baseler HA, Morland AB, Wandell BA (1999) Topographic organization of human visual areas in the absence of input from primary cortex. J Neurosci 19:2619-2627. Medline

Berman RA, Wurtz RH (2010) Functional identification of a pulvinar path from superior colliculus to cortical area MT. J Neurosci 30:6342-6354. CrossRef Medline

Berman RA, Wurtz RH (2011) Signals conveyed in the pulvinar pathway from superior colliculus to cortical area MT. J Neurosci 31:373-384. CrossRef Medline

Campbell FW, Green DG (1965) Optical and retinal factors affecting visual resolution. J Physiol 181:576-593. Medline

Campbell FW, Robson JG (1968) Application of Fourier analysis to the visibility of gratings. J Physiol 197:551-566. Medline

Cowey A, Stoerig P, Perry VH (1989) Transneuronal retrograde degeneration of retinal ganglion cells after damage to striate cortex in macaque monkeys: selective loss of $\mathrm{Pb}$ cells. Neuroscience 29:65-80. CrossRef Medline

Das A, Huxlin KR (2010) New approaches to visual rehabilitation for cortical blindness: outcomes and putative mechanisms. Neuroscientist 16: 374-387. CrossRef Medline

Das A, Demagistris M, Huxlin KR (2012) Different properties of visual relearning after damage to early versus higher-level visual cortical area. J Neurosci 32:5414-5425. CrossRef Medline

Desimone R, Schein SJ (1987) Visual properties or neurons in area V4 of the macaque: sensitivity to stimulus form. J Neurophysiol 57:835-868. Medline

Dosher BA, Lu ZL (1999) Mechanisms of perceptual learning. Vision Res 39:3197-3221. CrossRef Medline

Fahle M, Poggio T (2002) Perceptual learning. Cambridge, MA: MIT.

Fiorentini A, Berardi N (1980) Perceptual learning specific for orientation and spatial frequency. Nature 287:43-44. CrossRef Medline

Gegenfurtner KR, Kiper DC, Fenstemaker SB (1996) Processing of color, form, and motion in macaque area V2. Vis Neurosci 13:161-172. CrossRef Medline

Gegenfurtner KR, Kiper DC, Levitt JB (1997) Functional properties of neurons in macaque area V3. J Neurophysiol 77:1906-1923. Medline

Goebel R, Muckli L, Zanella FE, Singer W, Stoerig P (2001) Sustained extra- 
striate cortical activation without visual awareness revealed by fMRI studies in hemianopic patients. Vision Res 41:1459-1474. CrossRef Medline

Gutteridge IF, McDonald RA (2004) Hemianopic visual field loss as the first clinical evidence of occipital arteriovenous malformation. Clin Exp Optom 87:394-399. CrossRef Medline

Hayes RD, Merigan WH (2007) Mechanisms of sensitivity loss due to visual cortex lesions in humans and macaques. Cereb Cortex 17:1117-1128. Medline

Hendry SH, Reid RC (2000) The koniocellular pathway in primate vision. Ann Rev Neurosci 23:127-153. CrossRef Medline

Hess RF, Pointer JS (1989) Spatial and temporal contrast sensitivity in hemianopia: a comparative study of the sighted and blind hemifields. Brain 112:871-894. CrossRef Medline

Huang CB, Zhou Y, Lu ZL (2008) Broad bandwidth of perceptual learning in the visual system of adults with anisometropic amblyopia. Proc Natl Acad Sci U S A 105:4068-4073. CrossRef Medline

Huxlin KR, Martin T, Kelly K, Riley M, Friedman DI, Burgin WS, Hayhoe M (2009) Perceptual re-learning of complex visual motion after V1 damage in humans. J Neurosci 29:3981-3991. CrossRef Medline

Jeter PE, Dosher BA, Petrov A, Lu ZL (2009) Task precision at transfer determines specificity of perceptual learning. J Vis 9(3):1-13. CrossRef Medline

Karni A, Sagi D (1991) Where practice makes perfect in texture discrimination: evidence for primary visual cortex plasticity. Proc Natl Acad Sci U S A 88:4966-4970. CrossRef Medline

Kelly DH (1975) Spatial frequency selectivity in the retina. Vision Res 15: 665-672. CrossRef Medline

Kelly DH (1979) Motion and vision. II. Stabilization spatio-temporal threshold surface. J Opt Soc Am 69:1340-1349. CrossRef Medline

Leh SE, Ptito A, Schönwiesner M, Chakravarty MM, Mullen KT (2010) Blindsight mediated by an S-cone-independent collicular pathway: an fMRI study in hemispherectomized subjects. J Cogn Neurosci 22:670682. CrossRef Medline

Lu H, Qian N, Liu Z (2004) Learning motion discrimination with suppressed MT. Vision Res 44:1817-1825. CrossRef Medline

Morland AB, Ogilvie JA, Ruddock KH, Wright JR (1996) Orientation discrimination is impaired in the absence of the striate cortical contribution to human vision. Proc Biol Sci 263:633-640. CrossRef Medline

Morland AB, Jones SR, Finlay AL, Deyzac E, Lê S, Kemp S (1999) Visual perception of motion, luminance and color in a human hemianope. Brain 122:1183-1198. CrossRef Medline

Newsome WT, Paré EB (1988) A selective impairment of motion perception following lesions of the middle temporal visual area (MT). J Neurosci 8:2201-2211. Medline

Pasternak T (1990) Vision following loss of cortical directional selectivity. In: Comparative perception, basic mechanisms, vol. 1 (Berkley M, Stebbins W, eds), pp 407-428. New York: Wiley.

Pasternak T, Leinen LJ (1986) Pattern and motion vision in cats with selective loss of cortical directional selectivity. J Neurosci 6:938-945. Medline

Pasternak T, Albano JE, Harvitt DM (1990) The role of directionally selective neurons in the perception of global motion. J Neurosci 10:30793086. Medline

Pasternak T, Tompkins J, Olson CR (1995) The role of striate cortex in visual function of the cat. J Neurosci 15:1940-1950. Medline

Pelli DG, Zhang L (1991) Accurate control of contrast on microcomputer displays. Vision Res 31:1337-1350. Medline

Pollock A, Hazelton C, Henderson CA, Angilley J, Dhillon B, Langhorne P, Livingstone K, Munro FA, Orr H, Rowe FJ, Shahani U (2011) Interventions for visual field defects in patients with stroke (review). In: The Cochrane library (Group CS, ed), pp 1-83. Hoboken, NJ: Wiley.

Raninen A, Vanni S, Hyvärinen L, Näsänen R (2007) Temporal sensitivity in a hemianopic visual field can be improved by long-term training using flicker stimulation. J Neurol Neurosurg Psychiatry 78:66-73. Medline

Rodman HR, Gross CG, Albright TD (1989) Afferent basis of visual response properties in area MT of the macaque. I. Effects of striate cortex removal. J Neurosci 9:2033-2050. Medline

Rodman HR, Gross CG, Albright TD (1990) Afferent basis of visual response properties in area MT of the macaque. II. Effects of superior colliculus removal. J Neurosci 10:1154-1164. Medline
Roufs JA (1972) Dynamic properties of vision: 1. Experimental relationship between flicker and flash thresholds. Vision Res 12:261-278. CrossRef Medline

Sagi D (2011) Perceptual learning in vision research. Vision Res 51:1552_ 1566. CrossRef Medline

Sagi D, Tanne D (1994) Perceptual learning: learning to see. Curr Opin Neurobiol 4:195-199. CrossRef Medline

Sahraie A, Trevethan CT, Weiskrantz L, Olson J, MacLeod MJ, Murray AD, Dijkhuizen RS, Counsell C, Coleman R (2003) Spatial channels of visual processing in cortical blindness. Eur J Neurosci 18:1189-1196. CrossRef Medline

Sahraie A, Trevethan CT, MacLeod MJ, Murray AD, Olson JA, Weiskrantz L (2006) Increased sensitivity after repeated stimulation of residual spatial channels in blindsight. Proc Natl Acad Sci U S A 103:14971-14976. CrossRef Medline

Sahraie A, Trevethan CT, MacLeod MJ (2008) Temporal properties of spatial channels of processing in hemianopia. Neuropsychologia 46:879885. CrossRef Medline

Sahraie A, MacLeod MJ, Trevathan CT, Robson S, Olson JA, Callaghan P, Yip B (2010a) Improved detection following neuro-eye therapy in patients with post-geniculate damage. Exp Brain Res 206:25-34. CrossRef

Sahraie A, Hibbard PB, Trevethan CT, Ritchie KL, Weiskrantz L (2010b) Consciousness of the first order in blindsight. Proc Natl Acad Sci U S A 107:21217-21222. CrossRef Medline

Schmid MC, Mrowka SW, Turchi J, Saunders RC, Wilke M, Peters AJ, Ye FQ, Leopold DA (2010) Blindsight depends on the lateral geniculate nucleus. Nature 466:373-377. CrossRef Medline

Schoups AA, Vogels R, Orban GA (1995) Human perceptual learning in identifying the oblique orientation: retinotopy, orientation specificity and monocularity. J Physiol 483:797-810. Medline

Schoups A, Vogels R, Qian N, Orban G (2001) Practising orientation identification improves orientation coding in V1 neurons. Nature 412:549_ 553. CrossRef Medline

Seitz A, Watanabe T (2005) A unified model for perceptual learning. Trends Cogn Sci 9:329-334. CrossRef Medline

Sincich LC, Park KF, Wohlgemuth MJ, Horton JC (2004) Bypassing V1: a direct genicular input fo area MT. Nat Neurosci 7:1123-1128. CrossRef Medline

Sowden PT, Rose D, Davies IR (2002) Perceptual learning of luminance contrast detection: specific for spatial frequency and retinal location but not orientation. Vision Res 42:1249-1258. CrossRef Medline

Tamietto M, Cauda F, Corazzini LL, Savazzi S, Marzi CA, Goebel R, Weiskrantz L, de Gelder B (2010) Collicular vision guides nonconscious behavior. J Cogn Neurosci 22:888-902. CrossRef Medline

Thompson B, Liu Z (2006) Learning motion discrimination with suppressed and un-suppressed MT. Vision Res 46:2110-2121. CrossRef Medline

Wang R, Zhang JY, Klein SA, Levi DM, Yu C (2012) Task relevancy and demand modulate double-training enabled transfer of perceptual learning. Vision Res 61:33-38. CrossRef Medline

Watson AB, Ahumada AJ Jr (2005) A standard model for foveal detection of spatial contrast. J Vis 5(9):717-740. CrossRef Medline

Weiskrantz L, Warrington EK, Sanders MD, Marshall J (1974) Visual capacity in the hemianopic field following a restricted occipital ablation. Brain 97:709-728. CrossRef Medline

Weiskrantz L, Harlow A, Barbur JL (1991) Factors affecting visual sensitivity in a hemianopic subject. Brain 114:2269-2282. CrossRef Medline

Weiskrantz L, Barbur JL, Sahraie A (1995) Parameters affecting conscious versus unconscious visual discrimination with damage to the visual cortex (v1). Proc Natl Acad Sci U S A 92:6122-6126. CrossRef Medline

Xiao LQ, Zhang JY, Wang R, Klein SA, Levi DM, Yu C (2008) Complete transfer of perceptual learning across retinal locations enabled by double training. Curr Biol 18:1922-1926. CrossRef Medline

Zhang JY, Zhang GL, Xiao LQ, Klein SA, Levi DM, Yu C (2010) Rule-based learning explains visual perceptual learning and its specificity and transfer. J Neurosci 30:12323-12328. CrossRef Medline

Zhang T, Xiao LQ, Klein SA, Levin DM, Yu C (2010) Decoupling location specificity from perceptual learning of orientation discrimination. Vision Res 50:368-374. CrossRef Medline 